BULLETIN Bulletin hispanique

HISPANIQUE Université Michel de Montaigne Bordeaux

123-1 | 2021

La forma de vida cortesana en la literatura de la Edad Media y el Siglo de Oro

\title{
Mireia Aldomà García, ed., Primera parte de las Cien novelas de Giraldi Cinthio
}

Barcelona: Universo de Letras, 2019

\section{Guillermo Serés Guillén}

\section{OpenEdition \\ Journals}

\section{Edición electrónica}

URL: https://journals.openedition.org/bulletinhispanique/13194

DOI: 10.4000/bulletinhispanique.13194

ISSN: 1775-3821

Editor

Presses universitaires de Bordeaux

Edición impresa

Fecha de publicación: 20 junio 2021

Paginación: 384-388

ISBN: 979-10-300-0697-1

ISSN: 0007-4640

Referencia electrónica

Guillermo Serés Guillén, «Mireia Aldomà García, ed., Primera parte de las Cien novelas de Giraldi Cinthio», Bulletin hispanique [En línea], 123-1 | 2021, Publicado el 20 junio 2021, consultado el 02 julio 2021.

URL: http://journals.openedition.org/bulletinhispanique/13194 ; DOI: https://doi.org/10.4000/

bulletinhispanique.13194

Este documento fue generado automáticamente el 2 julio 2021.

Tous droits réservés 


\title{
Mireia Aldomà García, ed., Primera parte de las Cien novelas de Giraldi Cinthio
}

Barcelona: Universo de Letras, 2019

\author{
Guillermo Serés Guillén
}

\section{REFERENCIA}

Mireia Aldomà García, ed., Primera parte de las Cien novelas de Giraldi Cinthio. Barcelona: Universo de Letras, 2019, 324 páginas. ISBN 978-8418036651.

1 Mucha difusión alcanzó la traducción de Luis Gaytán de Vozmediano (Toledo, Pedro

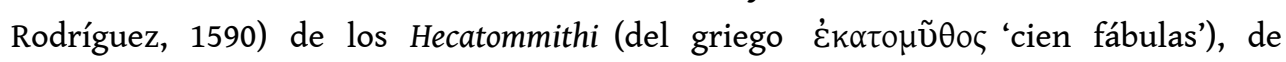
Giambatista Giraldi Cintio (Ferrara, 1504-1573), un celebérrimo noveliere y riguroso preceptista cuyas obras se difundieron por toda Europa. Aquellas cien fábulas las enmarca el ferrarés en un viaje (traduce Gaytán) de "una ilustre compañía de gentiles hombres y damas romanas", de Roma a Marsella, que, como se ve a simple vista, resulta ser un trasunto de la florentina compañía del Decameron de Boccaccio, modelo declarado por el autor. No huyen de la peste, como los florentinos, sino de las consecuencias del Saco de Roma de 1527. La excelente edición de la profesora Aldomà consta de un estupendo prefacio de la profesora $M^{a}$ Luisa Cerrón Puga (pp. 9-11), que da las principales claves de interpretación y fortuna de la obra de Giraldi Cintio, aquilata su proyección y señala sumariamente las peripecias de la censura: había ido directamente a las listas previas del Índice romano (por res lascivia) de 1580, pero se acabó imprimiendo sin expurgos en 1593 y 1608. A continuación, la introducción consta de las siguientes partes.

2 1.- Descripción bibliográfica de la edición toledana, redactada con todo detalle codicológico y señalando la ubicación bibliotecaria de los ejemplares; a continuación describe las doce ediciones italianas previas, desde la princeps de 1565 (pp. 13-16). En el 
capítulo 2.- "Publicación y éxito de la obra", pp. 17-18) señala el precedente bocachesco, con las enmiendas y sin los "defectos morales" (p. 18) de que adolecía el Decameron, especialmente la citada lascivia, prohibida expresamente por Trento, y el protagonismo de curas y frailes; el resto de características (disposición, materia, cotidianeidad, lenguaje, número de cuentos, etc.) sí las toma de Boccaccio, eventualmente para "tergiversarlo". Dedica el capítulo 3 (pp. 19-21) al marco narrativo, porque este aspecto es en el que está más en deuda con el de Certaldo, aunque aquí los diversos y respectivos narradores no se recluyen para huir de alguna epidemia, sino de que van de viaje, huyendo del citado "Sacco di Roma". Con todo, el marco no es un mero encuadre narrativo, sino que "tiene un valor simbólico y estético: reflexiones sobre el mundo y el arte, una poética o tratado de la época y un locus amoenus entre tanta desolación" (p. 20). En ese sentido, el marco de Giraldi es también un pretexto para probar argumentos, ajustándose escrupulosamente al procedimiento retórico de la quaestio finita y las respectivas responsiones, que son los exempla mismos, o sea, la parte del león de las novelle.

3 En el capítulo 4. ("El Saco de Roma", pp. 23-28) ya entra en materia. Nos recuerda que, aparte el saqueo, los testimonios contemporáneos señalan que aquellos días (6-13 de mayo de 1527) Roma fue escenario de una bacanal de orgías, destrucciones, profanaciones de iglesias, sacrilegios y desmanes sin tasa. El episodio se silenció en España e incluso la obra que lo refiere de Alfonso de Valdés (Diálogo de las cosas ocurridas en Roma, 1529) fue prohibida; así como las alusiones que figuran en La Lozana andaluza, de Francisco Delicado. El traductor de Giraldi lo omite, conocedor del silencio oficial y de la prohibición de la obra de Valdés; Gaytán prefiere autocensurarse para "evitar que su libro o no salga a la luz o lo haga para tener pronto una orden de la Inquisición" (p. 26). A salvo quedan testimonios populares, como un vivo romance que transcribe la estudiosa (pp. 26-28), donde figuran detalles truculentos del saqueo de Roma, que la Inquisición no pudo expurgar por su difusión oral. En el capítulo 5.- ("Estructura y oralidad", pp.29-30) analiza la dispositio, cuya estructura es también deudora de Boccaccio, ya que la obra está dividida, como el Decameron, en diez décadas o jornadas; con todo, introduce novedades, pues Giraldi concibe su obra "casi como una miscelánea o enciclopedia en la que incorpora múltiples y heterogéneos elementos, como son una larga introducción filosófica, los Diálogos de la vida civil, los numerosos poemas procedentes del Orlando furioso" (p. 29), entre otros. Esta incorporación la permite el sabio uso de la oralidad, dirigida por una suerte de magister, Fabio, noble encargado de "mover los hilos de la tramoya", porque "sus órdenes, sentencias y edad le confieren gran prestigio" (ibidem). Otra característica que confiere la ficción de oralidad es la incorporación de poemas y canciones, y escenas de lo cotidiano, de la vida cortesana, en la novella. Un componente que tendrá muy en cuenta nuestro "raro inventor", Cervantes, para las suyas.

El capítulo 6.- ("Los poemas en la Primera parte de las Cien novelas", pp. 31-36) lo dedica Aldomà al Giraldi poeta, señalando que el procedimiento de combinar prosa y verso no es novedoso, pues desde antiguo se dio el prosimetrum, además del Decameron y del Ninfale, del citado Boccaccio, o incluso la Vita nuova de Dante. Describe con riguroso pormenor los poemas (pp. 32-35), recordando la condición de poeta del italiano y señala los poemas españoles que incorpora el traductor Gaytán, citando especialmente los de Valdivielso y Luis de la Cruz. En el capítulo 7.- ("Argumentos y materia para el público", pp. 37-49) subraya "el aumento de la materia contemporánea en la novella y el gusto por el realismo, en detrimento de los elementos sobrenaturales e idealistas" (p. 37). La 
misma producción novelística "creó" un público lector, o sea, un hábito de lectura en un gran sector de receptores, que acabaron prefiriendo relatos de sucesos, situaciones, lugares o tiempos que les resultasen familiares, así como "una nueva literatura de ficción entretenida, amena y que resulte ligera" (ibidem). Giraldi ya da la pauta en el marco introductorio, señalando los dos extremos del amor (neoplatónico y lascivo) entre los cuales desplegará muchas variantes; una casuística que demuestra "que los ejemplos prácticos reclamados por los personajes se oponen drásticamente a las teorías enunciadas" (p. 39). Describe Aldomà la tipología en torno a dos ejes: "triunfo de la cortesana" (ejemplos I, III, V y VIII) y "derrota de la cortesana" (II, IV, VI, VII y IX) (p. 41). En las páginas siguientes (42-49) detalla las novelas con elementos eróticos, las que no abordan el tema del amor, las que arrancan de un matrimonio secreto, las de ambiente palaciego y las de personajes comunes, o sea, de personas corrientes, cotidianas "no príncipes ni reyes" (p. 48).

5 En el capítulo 8.- (“Conclusión”, pp. 51-52) analiza la convivencia del amor de raíz petrarquista, con el que depende de la filosofía neoplatónica y con el lascivo, "heredado de los relatos populares y del Decameron de Boccaccio"; la parte más censurada en la versión española es el "tema del amor lascivo, que toma cuerpo en las cortesanas, el amor pestífero que ofrecen las prostitutas, mujeres pintadas como mentirosas, infieles y dueñas de mil artificios (p.51). También incide en la solvencia con que Giraldi estructura sus novelle en el cañamazo de ejercicios retóricos, "respuestas y juegos de controversia" (p. 51). Las argumentationes y disputationes no le restan frescura a los relatos; las suele poner al servicio del "propósito moral y del ejercicio estilístico" (p.52). El traductor no se desvía de aquel fin, sino que tiende a "aumentar el tono moralizante" (ibidem). Cierra la estupenda introducción señalando que, a pesar de "la amplia difusión y el conocimiento que en España se tenía de las novelas y poemas italianos en el siglo XVI", va a ser un español, Cervantes, "raro inventor", el que revitalice un género italiano por excelencia que fue perdiendo vitalidad, de modo que el influjo será a la inversa, y autores posteriores, como Cialdini, Pallavicino y Malipiero "toman como modelo la narrativa española para superar transitoriamente la crisis del género" (p. 52).

6 Si analizamos someramente la edición de la traducción en sí, el argumento nos señala el horaciano utilis dulcisque ("lo dulce con lo provechoso y lo alegre con lo grave"): por una parte, el carácter moral, ejemplarizante, de la colección, dirigida a jóvenes inexpertos, para que sepan cómo "deben regirse los amorosos casos y juveniles deseos por el maduro juicio"; por otra, "podrá ser finalmente que lo que escribo no desagrade, sino que dé gusto a los que la mejor forma del humano trato seguir procuran" (p. 66). La bien traducida introducción nos señala el marco narrativo: "Ya començaba el sereno cielo a bordarse de color rojo y grana, [...] cuando la ilustre compañía se había escapado del estrago, confusión y muertes de que estaba llena, como ya diximos, la insigne Roma" (p. 71). La editora, con buen tino, separa el argumento con que enmarca cada ejemplo, como, por citar alguno, el del "exemplo IX": "Gineta ama a micer Juan de Buda; indúzele con engaño a que mate a su muger y ella, visto el peligro, huye; pero después de algún tiempo el marido conoce su inocencia y la maldad de Gineta, y así van de allí adelante juntos en el amor y contento que primero" (p. 142). En la nota al pie señala que sigue fielmente el original italiano; documenta el probable origen bocachesco de la protagonista, señala el motivo folclórico (K2112), cuya presencia también constata en otras colecciones: Bandello, Granucci, Malespini, Ascanio de' Mori, 
Ariosto e incluso en el Patrañuelo, de Timoneda. Este exhaustivo proceder se puede constatar en todos y cada uno de los ejemplos.

7 Por otra parte, el prólogo a lector del traductor es por sí mismo una buena pieza retórica que recuerda vivamente al de don Juan Manuel al Lucanor, pues tanto éste como aquél apelan a la diversidad de lectores, o de oyentes, que justifican la variatio de los cuentos, los diversos registros, los niveles de lectura, la complejidad de interpretación, "porque así como los ánimos y cuerpos de los hombres nunca son conforme y semejantes en todo, y por maravilla en alguna parte, [...] así en los ingenios y en las inclinaciones se halla también desemejança muy notable. [...] Cuales son inclinados a historias verdaderas y cuales a cuentos fabulosos" (p. 61). En segundo lugar justifica la poda de "lo que notablemente era lascivo y deshonesto", de ahí la ausencia de toda una novela, la segunda de la primera década, "en cuyo lugar puse la del maestro que enseña a amar, tomada de las ciento que recopiló el Sansovino". El otro autoexpurgo del traductor se refiere al "Saco de Roma, que se quitó para evitar algunos inconvenientes que pudieran seguirse de imprimirle" (ibidem). La tercera intención fue animar a los españoles a escribir novelas originales, o sea, que "hagan lo que nunca han hecho, que es componer novelas" (p. 62). Le va a tomar la palabra, y muy dignamente, como sabemos, Cervantes.

8 La lengua de llegada de la traducción es muy flexible y recoge muy bien la de origen, sea por la cercanía de las dos, sea por la pericia del traductor, que es capaz de verter estupendamente la sermocinatio original, los giros argumentales, los diálogos, las narraciones y descripciones, con una riqueza léxica encomiable, como se deja ver en cualquier fragmento, que elijo al azar: “¡Ay dulce Philania mía!, ¿cómo pudo caber en vuestro entendimiento el imaginar que yo os hubiese desdeñado? ¿No sabéis que sois mi alma y que toda alegría sin vos me sería pesada y enojada? Vuelto de aquí al niño, que era hermoso en gran manera, le besó dulcemente y, mirando a la madre, prosiguió diciendo: ¿qué hijo, vida mía, es éste, para que no deba yo amar por él a quien me hizo su padre?" (p. 317).

9 La rigurosa, cuidada y bien anotada edición ocupa las páginas 59-322. Las seiscientas notas de la estudiosa aclaran léxicamente; contextualizan el pasaje; presentan los realia; identifican personajes y hechos históricos; recuerdan los motivos folclóricos o tradicionales y las fuentes; traen algunos paralelos y eventualmente el cotejo con el original, y remiten a la bibliografía o fuentes secundarias, de cuyas principales interpretaciones críticas da cuenta la editora. Nos ofrece una buena transcripción, con la puntuación y acentuación actual, al igual que las grafías, aunque ha mantenido "x", "z", "ç", "nn" o "ll"; también mantiene alguna alternancia vocálica: "quiriendo" / "queriendo", “mujer" / "muger", "doncella" / "donzella”, y algunos grupos consonánticos cultos ("delictos"). Son tan lícitos estos criterios como otros análogos. La selecta y actualizada y específica bibliografía (pp. 53-57) da cuenta de los principales estudios, tanto italianos como españoles, sobre Giraldi, la novella, su difusión y su recepción en España.

10 Estamos, pues, de enhorabuena, por la excelente edición, que buena falta hacía, de la traducción de los cuentos de Giambattista Giraldi Cinzio, que tanta difusión alcanzaron en nuestro Siglo de Oro y en toda Europa. Bienvenida sea. 


\section{AUTORES}

\section{GUILLERMO SERÉS GUILLÉN}

Universitat Autònoma de Barcelona 